Keywords: colonic neoplasms; colorectal surgery; postoperative complications; survival; outcomes research; health services research

\title{
The impact of age on complications, survival, and cause of death following colon cancer surgery
}

Christopher T Aquina ${ }^{*}{ }^{1}$, Supriya G Mohile ${ }^{2}$, Mohamedtaki A Tejani ${ }^{2}$, Adan Z Becerra ${ }^{1}$, Zhaomin Xu ${ }^{1}$, Bradley J Hensley ${ }^{1}$, Reza Arsalani-Zadeh ${ }^{1}$, Francis P Boscoe ${ }^{3}$, Maria J Schymura ${ }^{3}$, Katia Noyes ${ }^{1}$, John RT Monson ${ }^{1,4}$ and Fergal J Fleming ${ }^{1}$

${ }^{1}$ Surgical Health Outcomes and Research Enterprise (SHORE), Department of Surgery, University of Rochester Medical Center, Rochester, NY 14642, USA; ${ }^{2}$ Division of Hematology/Oncology, Department of Medicine, University of Rochester Medical Center, Rochester, NY 14642, USA; ${ }^{3}$ New York State Cancer Registry, New York State Department of Health, Albany, NY 12204, USA and ${ }^{4}$ Center for Colon and Rectal Surgery, Florida Hospital Medical Group, University of Central Florida College of Medicine, Orlando, FL 32803, USA

Background: Given scarce data regarding the relationship among age, complications, and survival beyond the 30-day postoperative period for oncology patients in the United States, this study identified age-related differences in complications and the rate and cause of 1 -year mortality following colon cancer surgery.

Methods: The NY State Cancer Registry and Statewide Planning and Research Cooperative System identified stage I-III colon cancer resections (2004-2011). Multivariable logistic regression and survival analyses assessed the relationship among age $(<65,65-74, \geqslant 75)$, complications, 1-year survival, and cause of death.

Results: Among 24426 patients surviving > 30 days, 1-year mortality was $8.5 \%$. Older age groups had higher complication rates, and older age and complications were independently associated with 1 -year mortality $(P<0.0001)$. Increasing age was associated with a decrease in the proportion of deaths from colon cancer with a concomitant increase in the proportion of deaths from cardiovascular disease. Older age and sepsis were independently associated with higher risk of colon cancer-specific death (65-74: $\mathrm{HR}=1.59,95 \% \mathrm{Cl}=1.26-2.00 ; \geqslant 75: \mathrm{HR}=2.57,95 \% \mathrm{Cl}=2.09-3.16$; sepsis: $\mathrm{HR}=2.58,95 \% \mathrm{Cl}=2.13-3.11)$ and cardiovascular disease-specific death $(65-74: \mathrm{HR}=3.72,95 \% \mathrm{Cl}=2.29-6.05 ; \geqslant 75: \mathrm{HR}=7.02,95 \% \mathrm{Cl}=4.44-11.10 ;$ sepsis: $\mathrm{HR}=2.33$, $95 \% \mathrm{Cl}=1.81-2.99)$.

Conclusions: Older age and sepsis are associated with higher 1-year overall, cancer-specific, and cardiovascular-specific mortality, highlighting the importance of geriatric assessment, multidisciplinary care, and cardiovascular optimisation for older patients and those with infectious complications.

Given that colorectal cancer is the second-leading cause of cancerrelated death and that the older population continues to grow in the United States, it is anticipated that the number of older patients with colon cancer will increase (Siegel et al, 2014). In fact, approximately two-thirds of cancer survivors will be $\geqslant 65$ years old by the year 2020 (Mohile et al, 2016). Postoperative mortality is an important outcome measure following colon cancer surgery, especially for high-risk groups such as the elderly. However, while most studies in the United States have focused on 30-day postoperative mortality as an end point, there is increasing

*Correspondence: Dr CT Aquina; E-mail: christopher_aquina@urmc.rochester.edu

Received 14 August 2016; revised 4 November 2016; accepted 13 November 2016; published online 5 January 2017

(c) 2017 Cancer Research UK. All rights reserved 0007 - 0920/17 
evidence from Europe to suggest that there is high mortality beyond 30 days in the older population (Gooiker et al, 2012; Mamidanna et al, 2012a; Byrne et al, 2013). In fact, this excess postoperative mortality has been shown to endure up to 1 year following surgery and has been suggested to be the most important explanatory factor for age-related differences in long-term colorectal cancer survival (Dekker et al, 2011).

Although only a limited number of studies have examined postoperative mortality beyond 30 days, there is even less data regarding age-related differences in complications and cause of death at 1 year. In the only population-based study investigating 1 -year mortality and cause of death, Dekker et al observed that mortality increased with age and $25 \%$ of deaths were attributable to complications among 1924 patients who underwent stage I-III colorectal cancer resection in The Netherlands (Dekker et al, 2014). Furthermore, older patients may be at higher risk for septic complications, and there is increasing evidence that sepsis is associated with worse long-term survival following colorectal cancer surgery as well as an increased risk of cardiovascular events due to a sepsis-mediated systemic inflammatory response (Yende et al, 2014; Aquina et al, 2016a; Ou et al, 2016; Park et al, 2016). However, no similar studies to date have been performed in the United States.

Evaluating the association among age, complications, long-term mortality, and cause of death may help identify patients at risk for adverse outcomes and guide both preoperative and postoperative strategies to optimise these high-risk patients. For example, the use of preoperative comprehensive geriatric assessment (CGA) to assess frailty and stratify risk has been shown to reduce the rate of complications, decrease hospital length of stay, and improve longterm quality of life (Huddleston et al, 2004; Ellis et al, 2011; Partridge et al, 2014). Prehabilitation, or strategies to optimise preoperative functional capacity in at-risk patients, can improve the rate of return to baseline functional status following surgery (Gillis et al, 2014). Finally, postoperative multidisciplinary care with comanagement by geriatricians for older patients has been shown to decrease the rate of complications, reduce length of stay, and increase the rate of chemotherapy completion for oncology patients (Huddleston et al, 2004; Partridge et al, 2014). However, it remains unclear as to which patients would most benefit from these interventions.

Given the scarce amount of data regarding 1-year mortality and cause of death in the United States, the aim of this present study was to examine age-related differences in postoperative complications, 1-year survival, and cause-specific mortality among patients in New York State using a linked population-based dataset between the state cancer registry and state hospital discharge database. Our hypothesis was that older age would be associated with higher odds of a postoperative complication, higher risk of 1-year mortality, and higher risk of both colon cancer cause-specific mortality and cardiovascular disease cause-specific mortality. This information could help direct the utilisation of CGA, prehabilitation, and multidisciplinary care for high-risk patients.

\section{MATERIALS AND METHODS}

NYSCR and SPARCS. The New York State Cancer Registry (NYSCR) and Statewide Planning and Research Cooperative System (SPARCS) were utilised for this study. The NYSCR has received the highest certification from the North American Association of Central Cancer Registries, and SPARCS is an allpayer hospital discharge database that contains patient-level data on all non-Veteran Affairs hospital admissions, ambulatory surgery procedures, and emergency department visits in New York State and has been used extensively for research purposes (Boscoe et al,
2011; Aquina et al, 2015a, b, c, d; Iannuzzi et al, 2016; Aquina et al, 2016b, c, d). The NYSCR is linked to Vital Records and the National Death Index to provide the cause and date of death for patients.

Study cohort selection. Patients who underwent colectomy (ICD-9 = 17.31-17.39, 45.71-45.79, or 45.8-45.83) for stage I-III colon adenocarcinoma (site ICD-O-3 = C180, C182-C189, C199, or SEER site recode $=21041-21051$; histology $=8140,8210-8221$, 8260-8263, or 8470-8490) diagnosed from 2004-2011 were identified within the NYSCR and SPARCS. Patients were excluded if they had missing data related to adjuvant therapy, the unique surgeon identifier, surgeon board-certification status, surgeon year of training completion, or TNM staging or if they died within 30 days of surgery.

Outcomes. The primary outcome was 1-year overall survival following surgery. Survival follow-up was complete through 31 December 2012, so each patient in the study cohort had 1 year of potential follow-up. Secondary outcomes included postoperative complications, cause of death, and 1-year cause-specific survival. Postoperative complications (anastomotic leak/gastrointestinal complication, abdominal abscess, surgical site infection, pneumonia, sepsis, pulmonary failure, myocardial infarction, venous thromboembolism, acute renal failure, gastrointestinal bleeding, and haemorrhage) were identified during the index admission as a diagnosis 'not present-on-admission' or upon readmission to any non-Veteran Affairs hospital in New York State within 30 days of surgery. For the cause-specific survival analyses, patients who died from a different cause were informatively censored on the date of death. The ICD-9 and ICD-10 codes used to identify complications and causes of death are listed in Supplementary Table 1.

Additional covariates. Patient factors considered for the analyses included age $(<65,65-74,>75)$, sex, insurance type, and unscheduled admission as defined by SPARCS. Elixhauser comorbidities were identified as present-on-admission for the index admission as well as any inpatient admission in the prior year to increase the capture rate of comorbidities (Quan et al, 2005). Oncologic factors included TNM/AJCC staging, tumour grade, and receipt of adjuvant chemotherapy. Operative factors included type of colectomy (left, right, partial, and total), a minimally invasive approach (ICD-9=17.31-17.39, 17.42, 45.81, $48.42,48.51,54.21,54.51$, or V64.41), and year of surgery.

Surgeon characteristics included board-certification type (surgery or colorectal surgery), years of experience, and annual colon cancer resection volume. Information on board-certification and year of residency/fellowship completion were obtained from the American Medical Association Masterfile and American Board of Medical Specialties databases. Surgeon annual colon cancer resection volume was characterised into tertiles (low, medium, and high volume).

Hospital factors included academic status, location, and annual colon cancer resection volume. Academic status was based upon the Council of Teaching Hospitals designation as obtained from the American Hospital Association Annual Survey. Urban or rural hospital location was based upon the definition by the US Office of Management and Budget (2013). Hospital annual colon cancer resection volume was characterised into tertiles (low, medium, and high volume).

Statistical analysis. Factors were compared by outcome using $\chi^{2}$-square test, Kaplan-Meier, and Cochran-Armitage test for trend analyses as appropriate to the data. Factors with $P<0.1$ on bivariate analysis were manually entered in multivariable analyses. Three-level mixed-effects multivariable analyses were performed to account for clustering of patients among surgeons and hospitals. Logistic regression analysis was utilised for the outcome of a postoperative complication, Cox proportional-hazards analysis was 
used for 1-year overall survival, and competing-risks analysis was used for cause-specific survival (Katsahian et al, 2006). The $\mathrm{R}$ packages glmer (logistic regression), coxme (Cox proportionalhazards), and frailtyPack (competing-risks) were used for the analyses ( $\mathrm{R}$ version 3.2.5, R Foundation for Statistical Computing). SAS, Version 9.2 (SAS Institute, Cary, NC, USA) was used for all other analyses. The study was approved by the University of Rochester Medical Center (IRB \#00054886) and New York Department of Health (DPRB \#1412-05) institutional review boards.

\section{RESULTS}

Cohort characteristics. A total of 30700 patients underwent stage I-III colon cancer resection of which 24426 patients met inclusion criteria. Of those excluded, 1224 had missing adjuvant therapy data, 11 had a missing unique surgeon identifier, 2986 had missing or no surgeon board-certification or year of training completion, and 59 had missing TNM staging. In addition, 883 (3.3\%) patients died within 30 days of surgery. The mean time of follow-up was 349 days (s.d. \pm 61 days) with a total of 24426 person-years of follow-up.

The study cohort characteristics by age group are presented in Table 1 . Age $\geqslant 75$ comprised the largest age group (44\%) followed by the $<65(32 \%)$ and $65-74(24 \%)$ age groups. Older patients were more likely to be female, of white race, and have higher comorbidity burden. They were also more likely to have an unscheduled admission for the colectomy, undergo an open operative approach, and have surgery at a non-academic or rural hospital. They were less likely to have stage III disease and receive adjuvant chemotherapy for stage III disease. Patients who had a postoperative complication were also less likely to receive chemotherapy for stage III disease $(39.4 \%$ vs $58.8 \%, P<0.0001)$.

Postoperative complications. After excluding those that died within 30 days, the complication rate for the study cohort was $29.7 \%(N=7595)$. Table 1 presents the captured frequency of each complication by age group. Sepsis was correlated with other complications that may act as sequelae of sepsis, including acute renal failure $(R=0.343)$ and pulmonary failure $(R=0.411)$. Increasing age was associated with a higher risk of a complication $(<65=22.6 \% ; 65-74=28.8 \%$; $\geqslant 75=35.5 \%$; $P<0.0001)$. Factors independently associated with a complication are presented in Table 2. After controlling for patient, surgeon, and hospital characteristics, age 65-74 (odds ratio $(\mathrm{OR})=1.34,95 \%$ confidence interval $(\mathrm{CI})=1.23-1.45)$ and age $\geqslant 75(\mathrm{OR}=1.62$, $95 \% \mathrm{CI}=1.50-1.74)$ were independently associated with higher odds of a complication compared to age $<65$.

One-year overall survival. Of those that survived at least 30 days $(N=24426)$, the overall 1 -year mortality rate was $8.5 \%$. Older age $(<65=2.8 \% ; \quad 65-74=6.4 \% ; \geqslant 75=13.9 \% ; P<0.0001)$ and $a$ postoperative complication $(16.2 \%$ vs $5.2 \% ; P<0.0001)$ conferred higher unadjusted rates of 1 -year mortality. Figure $1 \mathrm{~A}$ displays the 1 -year overall mortality rates by postoperative complication status stratified by age. In particular, sepsis had high unadjusted rates of 1 -year mortality across all age groups (overall unadjusted mortality rate $=35.7 \%$; Figure 1B). Table 2 presents factors independently associated with 1-year overall mortality. After controlling for patient, surgeon, and hospital characteristics, age 65-74 (hazard ratio $(\mathrm{HR})=2.04,95 \% \mathrm{CI}=1.73-2.41)$, age $\geqslant 75(\mathrm{HR}=3.49,95 \%$ $\mathrm{CI}=3.00-4.06)$, and a complication $(\mathrm{HR}=2.17,95 \% \mathrm{CI}=1.98$ 2.37) were independently associated with a higher risk of 1-year overall mortality.

Causes of death. Among the 2171 who died, the five most common causes of 1-year mortality in order were colon cancer
(45.6\%), cardiovascular disease $(24.5 \%)$, another primary cancer (7.4\%), respiratory disease $(6.4 \%)$, and infection $(3.5 \%)$. Table 3 presents the number and proportion of patients who died by cause of death stratified by AJCC stage and age group. Using a test for trend, increasing age was associated with a decrease in the proportion of patients who died from colon cancer $(P=0.0002)$ with a concomitant increase in the proportion of patients who died from cardiovascular disease $(P<0.0001)$. For stage $\mathrm{I}$, colon cancer was the most common cause of death for the $<65$ age group, and cardiovascular disease was the most common cause of death for the $65-74$ and $\geqslant 75$ age groups. For stage II and III, colon cancer was the most common cause of death across all age groups. Among those with sepsis (not shown in Table), colon cancer (41.5\%) and cardiovascular disease $(24.6 \%)$ were also the two most common causes of death.

One-year cause-specific survival. Competing-risks multivariable analyses were performed for 1-year colon cancer mortality and cardiovascular disease mortality since these were the two most common causes of death. The results of these analyses are shown in Table 4. Of note, older age and the infectious complications of sepsis, pneumonia, and abdominal abscess were independent risk factors for death from colon cancer. For death from cardiovascular disease, older age, sepsis, and pneumonia were independent risk factors.

\section{DISCUSSION}

This study investigated the relationship among age, postoperative complications, 1-year survival, and cause of death following potentially curative colon cancer surgery. Increasing age was independently associated with higher odds of a complication, and both increasing age and complications were independently associated with higher 1-year overall mortality as well as higher 1-year colon cancer and cardiovascular disease-specific mortality. In particular, infectious complications were associated with higher risk of death due to colon cancer and cardiovascular disease, and nearly one in four patients $\geqslant 75$ years old who suffered a complication died within 1 year. Furthermore, increasing age was associated with a decrease in the proportion of patients who died from colon cancer with a concomitant increase in the proportion of patients who died from cardiovascular disease. Given these relationships among age, complications, 1-year survival, and cause of death, these data highlight the importance of preoperative geriatric assessment, multidisciplinary patient care among surgeons, primary care physicians, and medical oncologists, and cardiovascular optimisation of older patients and those who suffer from sepsis.

Relation to other studies. Although this is the first large study in the United States to investigate 1-year survival and cause of death following colon cancer surgery, the 1-year mortality rate is similar to that of population-based European studies. One-year mortality rates ranged from 11.9 to $14 \%$ in studies from The Netherlands and the United Kingdom (Dekker et al, 2011, 2014; Gooiker et al, 2012; Mamidanna et al, 2012b). These rates are similar to the $11.6 \%$ 1-year overall mortality rate in the current study when including those who died within 30 days of surgery. In the only other study to also look at cause of death, Dekker et al observed that 1-year mortality increased with patient age, $75 \%$ of deaths were attributed to colorectal cancer, and $25 \%$ of deaths were attributed to postoperative complications among 1924 patients who underwent stage I-III colorectal cancer resection in The Netherlands between 2006 and 2008 (Dekker et al, 2014). Because the number of deaths coded as being due to colorectal cancer appeared too high to be due to cancer recurrence, the authors concluded that the excess mortality was due to a prolonged impact of surgery, especially in the elderly population. Using a similar 
Table 1. Patient, surgeon, and hospital characteristics and outcomes by age group

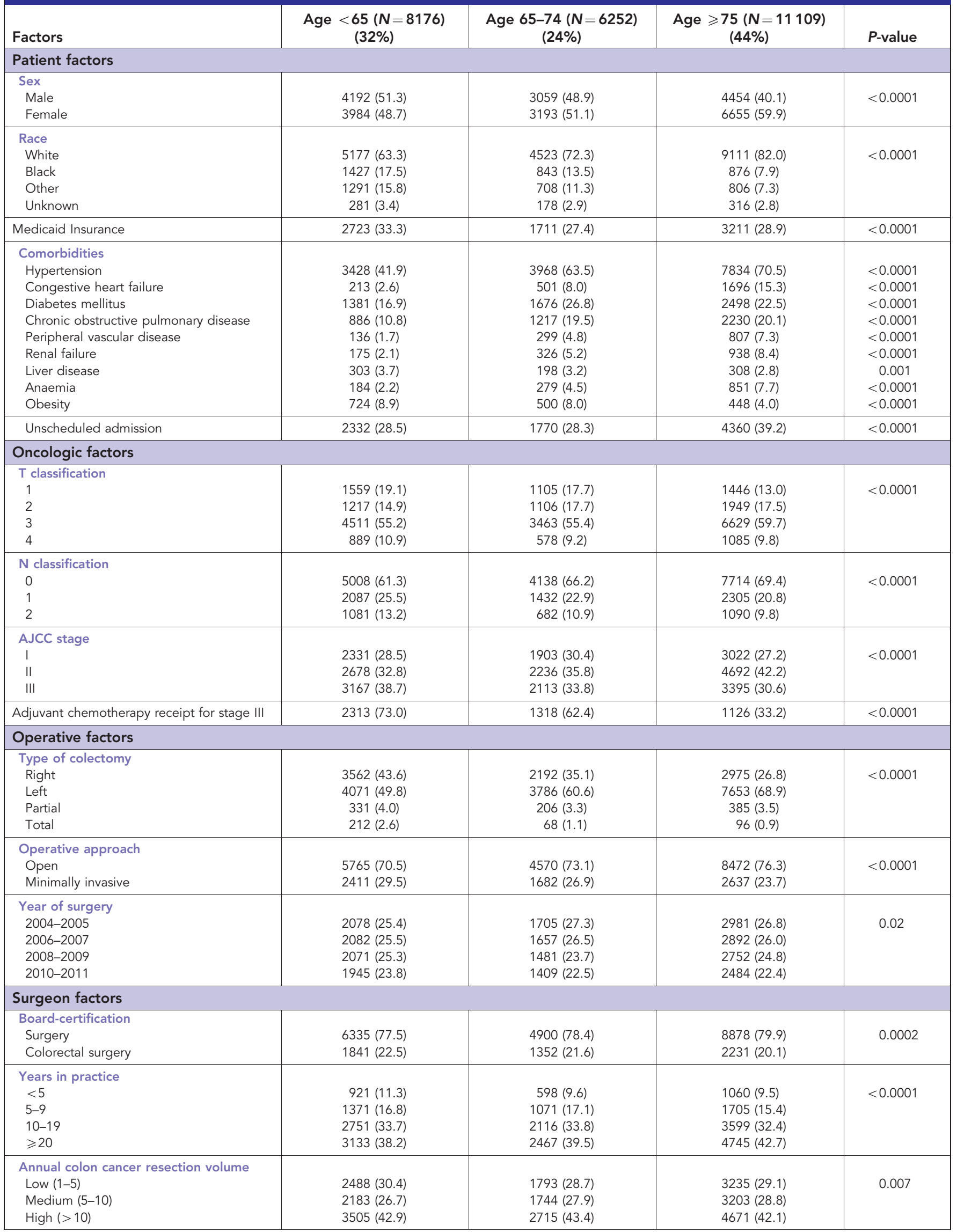




\begin{tabular}{|c|c|c|c|c|}
\hline Factors & $\begin{array}{c}\text { Age }<65(N=8176) \\
(32 \%)\end{array}$ & $\begin{array}{c}\text { Age } 65-74(N=6252) \\
(24 \%)\end{array}$ & $\begin{array}{c}\text { Age } \geqslant 75(N=11109) \\
(44 \%)\end{array}$ & $P$-value \\
\hline \multicolumn{5}{|l|}{ Hospital Factors } \\
\hline Major academic center & $3861(47.2)$ & $2811(45.0)$ & 4415 (39.7) & $<0.0001$ \\
\hline $\begin{array}{l}\text { Location } \\
\text { Urban } \\
\text { Rural }\end{array}$ & $\begin{array}{c}7716(94.4) \\
460(5.6)\end{array}$ & $\begin{array}{c}5812(93.0) \\
440(7.0)\end{array}$ & $\begin{array}{c}10255(92.3) \\
854(7.7)\end{array}$ & $<0.0001$ \\
\hline $\begin{array}{l}\text { Annual colon cancer resection volume } \\
\text { Low }(1-30) \\
\text { Medium }(31-55) \\
\text { High }(>55)\end{array}$ & $\begin{array}{l}2549(31.2) \\
2407(29.4) \\
3220(39.4)\end{array}$ & $\begin{array}{l}1910(30.6) \\
1879(30.0) \\
2463(39.4)\end{array}$ & $\begin{array}{l}3483(31.3) \\
3339(30.1) \\
4287(38.6)\end{array}$ & 0.63 \\
\hline \multicolumn{5}{|l|}{ Outcomes } \\
\hline $\begin{array}{l}\text { Major complication } \\
\text { Surgical site infection } \\
\text { Abdominal abscess } \\
\text { Anastomotic leak/Gl complication } \\
\text { Sepsis } \\
\text { Pneumonia } \\
\text { Pulmonary failure } \\
\text { Myocardial infarction } \\
\text { Venous thromboembolism } \\
\text { Acute renal failure } \\
\text { Gastrointestinal bleeding } \\
\text { Haemorrhage } \\
\text { Any major complication }\end{array}$ & $\begin{array}{r}610(7.5) \\
215(2.6) \\
816(10.0) \\
225(2.7) \\
18(0.2) \\
210(2.6) \\
40(0.5) \\
119(1.5) \\
196(2.4) \\
149(1.8) \\
83(1.0) \\
1852(22.6)\end{array}$ & $\begin{aligned} 503(8.0) \\
147(2.3) \\
736(11.8) \\
263(4.2) \\
48(0.8) \\
350(5.6) \\
87(1.4) \\
147(2.3) \\
363(5.8) \\
177(2.8) \\
87(1.4) \\
1798(28.8)\end{aligned}$ & $\begin{array}{c}855(7.7) \\
277(2.5) \\
1422(12.8) \\
626(5.6) \\
78(0.7) \\
928(8.3) \\
274(2.5) \\
323(2.9) \\
885(8.0) \\
642(5.8) \\
194(1.7) \\
3945(35.5)\end{array}$ & $\begin{aligned} & 0.43 \\
& 0.57 \\
< & 0.0001 \\
< & 0.0001 \\
< & 0.0001 \\
< & 0.0001 \\
< & 0.0001 \\
< & 0.0001 \\
< & 0.0001 \\
< & 0.0001 \\
& 0.0001 \\
< & 0.0001\end{aligned}$ \\
\hline 1-Year overall mortality & $226(2.8)$ & $401(6.4)$ & 1544 (13.9) & $<0.0001$ \\
\hline
\end{tabular}

A

No Complication

Complication

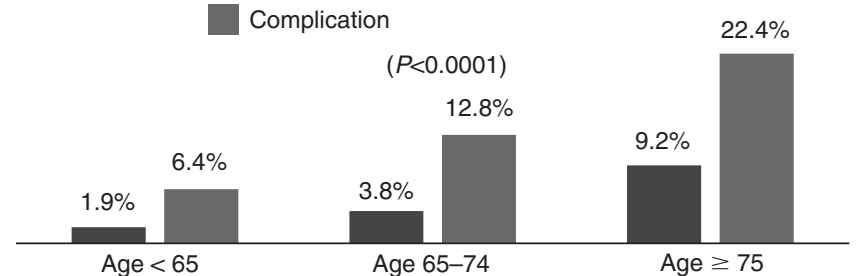

B

No sepsis

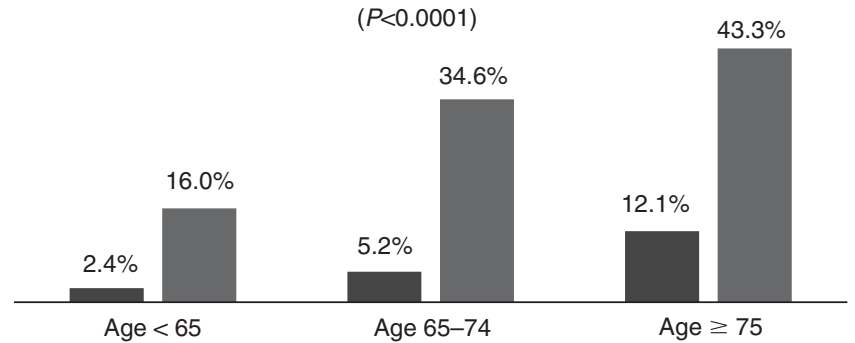

Figure 1. Bar graph depicting 1-year overall mortality rates by (A) postoperative complication status (yes/no) and (B) sepsis status (yes/no) stratified by age group ( $<65,65-74$, and $\geqslant 75$ years old).

study cohort, the same research group also found that older patients who survived at least 1 year following colorectal cancer surgery had similar long-term cancer-related survival to that of younger patients, suggesting that differences in long-term survival across age groups were due to deaths within the first postoperative year (Dekker et al, 2011). These findings, as well as that of the current study, highlight the importance of preoperative CGA and multidisciplinary care among healthcare providers in the postoperative period as these strategies may not only improve 1-year survival but also long-term survival in the older surgical population.

Strategies to improve survival. The benefits of CGA, which measure activities of daily living (ADLs), instrumental ADLs (IADLs), depression, cognition, nutrition, and physical performance, have been demonstrated for elderly patients admitted to the hospital (Extermann, 2010; Ellis et al, 2011). In a Cochrane metaanalysis of 10315 patients from 22 trials comparing CGA with standard care, patients who received CGA were less likely to suffer death or deterioration $(\mathrm{OR}=0.76,95 \% \mathrm{CI}=0.64-0.90)$, less likely to be institutionalised $(\mathrm{OR}=0.79,95 \% \mathrm{CI}=0.69-0.88)$, and more likely to be alive and in their own homes after 12 months of follow-up $(\mathrm{OR}=1.16,95 \% \mathrm{CI}=1.05-1.28$; Ellis et al, 2011). Although fewer studies have focused on the surgical population, a recent systematic review suggests that the use of CGA may reduce medical complications and length of stay following elective surgery (Partridge et al, 2014). In one of the randomised controlled trials included in the review, CGA reduced the rate of complications by $11.8 \%$ and the time to 'fit for discharge' by 0.5 days in patients undergoing elective orthopaedic surgery (Huddleston et al, 2004). In addition, the use of preoperative geriatric assessment markers to assess patient frailty has demonstrated good predictive ability for postoperative complications, discharge to a nursing facility, and 6-month mortality in patients undergoing major surgery (Robinson et al, 2009; Makary et al, 2010; Oresanya et al, 2014).

Determining which patients are at risk for adverse postoperative events using CGA can also help guide preoperative and postoperative management of surgical patients in several other ways. In the preoperative setting, given that a large proportion of older patients die from cardiovascular disease, CGA and cardiovascular optimisation before surgery could help prevent adverse events. In addition, selecting appropriate patients for prehabilitation may improve functional status and subsequent postoperative outcomes. In a randomised controlled trial that included 77 patients undergoing colorectal cancer resection, Gillis et al observed that a higher proportion of patients who underwent prehabilitation 
Table 2. Multivariable analyses of factors independently associated with postoperative complications and 1-year overall mortality

\begin{tabular}{|c|c|c|}
\hline & $\begin{array}{l}\text { Postoperative } \\
\text { complication* } \\
(\text { OR }(95 \% \mathrm{Cl}))\end{array}$ & $\begin{array}{c}\text { 1-Year overall } \\
\text { mortality } \\
(\mathrm{HR}(95 \% \mathrm{Cl}))\end{array}$ \\
\hline $\begin{array}{l}\text { Age } \\
\quad<65 \\
65-75 \\
\geqslant 75\end{array}$ & $\begin{array}{c}\text { Reference } \\
1.34(1.23-1.45) \\
1.62(1.50-1.74)\end{array}$ & $\begin{array}{c}\text { Reference } \\
2.04(1.73-2.41 \\
3.49(3.00-4.06)\end{array}$ \\
\hline Postoperative complication & N/A & $2.17(1.98-2.37)$ \\
\hline \multicolumn{3}{|l|}{ Other patient factors } \\
\hline $\begin{array}{l}\text { Sex } \\
\text { Female } \\
\text { Male }\end{array}$ & $\begin{array}{c}\text { Reference } \\
1.42(1.33-1.50)\end{array}$ & - \\
\hline $\begin{array}{l}\text { Race } \\
\text { White } \\
\text { Black } \\
\text { Other } \\
\text { Unknown }\end{array}$ & $\begin{array}{c}\text { Reference } \\
1.02(0.92-1.13) \\
0.88(0.79-0.98) \\
0.83(0.69-1.01)\end{array}$ & $\begin{array}{c}\text { Reference } \\
0.93(0.80-1.07) \\
0.85(0.72-1.01) \\
1.04(0.79-1.36)\end{array}$ \\
\hline Medicaid insurance & $1.14(1.06-1.22)$ & - \\
\hline $\begin{array}{l}\text { Comorbidities } \\
\text { Hypertension } \\
\text { Congestive heart failure } \\
\text { Chronic obstructive pulmonary disease } \\
\text { Renal failure } \\
\text { Peripheral vascular disease } \\
\text { Liver disease } \\
\text { Anaemia }\end{array}$ & $\begin{array}{c}0.93(0.88-0.99) \\
1.46(1.32-1.61) \\
1.27(1.17-1.37) \\
2.01(1.78-2.27) \\
1.02(0.90-1.16) \\
- \\
3.03(2.67-3.44)\end{array}$ & $\begin{array}{l}0.82(0.75-0.90) \\
1.60(1.43-1.78) \\
1.23(1.12-1.36) \\
1.39(1.22-1.59) \\
1.21(1.04-1.41) \\
1.59(1.29-1.95) \\
1.34(1.18-1.52)\end{array}$ \\
\hline Unscheduled admission & $2.04(1.91-2.18)$ & $1.93(1.76-2.13)$ \\
\hline \multicolumn{3}{|l|}{ Oncologic factors } \\
\hline $\begin{array}{l}\text { AJCC stage } \\
\text { I } \\
\text { II } \\
\text { III }\end{array}$ & $\begin{array}{l}- \\
- \\
-\end{array}$ & $\begin{array}{c}\text { Reference } \\
1.38(1.21-1.57) \\
2.44(2.14-2.79)\end{array}$ \\
\hline $\begin{array}{l}\text { T classification } \\
1 \\
2 \\
3 \\
4\end{array}$ & $\begin{array}{c}\text { Reference } \\
1.09(0.98-1.21) \\
1.06(0.97-1.15) \\
1.32(1.17-1.48)\end{array}$ & $\begin{array}{l}- \\
- \\
- \\
-\end{array}$ \\
\hline $\begin{array}{l}\text { Tumour grade } \\
1 \\
2 \\
3 / 4 \\
\text { Unknown }\end{array}$ & $\begin{array}{l}- \\
- \\
- \\
-\end{array}$ & $\begin{array}{c}\text { Reference } \\
1.02(0.86-1.21) \\
1.54(1.28-1.85) \\
1.33(1.01-1.75)\end{array}$ \\
\hline Receipt of adjuvant chemotherapy & - & $0.57(0.50-0.64)$ \\
\hline \multicolumn{3}{|l|}{ Operative factors } \\
\hline $\begin{array}{l}\text { Type of colectomy } \\
\text { Right } \\
\text { Left } \\
\text { Partial } \\
\text { Total }\end{array}$ & $\begin{array}{c}\text { Reference } \\
0.96(0.90-1.02) \\
1.39(1.191 .62) \\
1.89(1.51-2.38)\end{array}$ & $\begin{array}{c}\text { Reference } \\
1.03(0.93-1.13) \\
1.15(0.92-1.43) \\
1.35(0.94-1.92)\end{array}$ \\
\hline $\begin{array}{l}\text { Operative approach } \\
\text { Open } \\
\text { Minimally invasive }\end{array}$ & $\begin{array}{c}\text { Reference } \\
0.74(0.68-0.80)\end{array}$ & $\begin{array}{c}\text { Reference } \\
0.79(0.70-0.89)\end{array}$ \\
\hline $\begin{array}{l}\text { Year of surgery } \\
2004-2005 \\
2006-2007 \\
2008-2009 \\
2010-2011\end{array}$ & $\begin{array}{c}\text { Reference } \\
1.14(1.05-1.23) \\
1.28(1.18-1.39) \\
1.28(1.17-1.41)\end{array}$ & $\begin{array}{l}- \\
- \\
- \\
-\end{array}$ \\
\hline \multicolumn{3}{|l|}{ Surgeon factors } \\
\hline $\begin{array}{l}\text { Board-certification } \\
\text { Surgery } \\
\text { Colorectal surgery }\end{array}$ & $\begin{array}{c}\text { Reference } \\
1.02(0.91-1.14)\end{array}$ & $\begin{array}{c}\text { Reference } \\
0.84(0.73-0.97)\end{array}$ \\
\hline $\begin{array}{l}\text { Annual colon cancer resection volume } \\
\text { Low }(1-5) \\
\text { Medium }(6-10) \\
\text { High }(>10)\end{array}$ & $\begin{array}{c}\text { Reference } \\
0.92(0.85-1.00) \\
0.94(0.86-1.03)\end{array}$ & $\begin{array}{c}\text { Reference } \\
0.96(0.86-1.07) \\
0.87(0.78-0.98)\end{array}$ \\
\hline \multicolumn{3}{|l|}{ Hospital factors } \\
\hline $\begin{array}{l}\text { Annual colon cancer resection volume } \\
\text { Low (1-30) } \\
\text { Medium (31-55) } \\
\text { High }(>55)\end{array}$ & $\begin{array}{c}\text { Reference } \\
1.18(1.07-1.29) \\
1.04(0.93-1.17)\end{array}$ & $\begin{array}{c}\text { Reference } \\
0.90(0.80-1.02) \\
0.93(0.80-1.07)\end{array}$ \\
\hline
\end{tabular}

Table 3. Causes of death at 1 year by age group and AJCC stage

\begin{tabular}{|c|c|c|c|}
\hline Cause of death & Age $<65$ & $\begin{array}{c}\text { Age } \\
65-74\end{array}$ & Age $\geqslant 75$ \\
\hline Stage I ( $N=350$ deaths $)$ & $(N=26)$ & $(N=56)$ & $(N=268)$ \\
\hline Colon cancer & $9(34.6 \%)$ & $8(14.3 \%)$ & $61(22.8 \%)$ \\
\hline Cardiovascular disease & $5(19.2 \%)$ & $21(37.5 \%)$ & $108(40.3 \%)$ \\
\hline Respiratory disease & $2(7.7 \%)$ & $5(8.9 \%)$ & $26(9.7 \%)$ \\
\hline Other primary cancer & $3(11.5 \%)$ & $8(14.3 \%)$ & $21(7.8 \%)$ \\
\hline Infection & $1(3.8 \%)$ & $4(7.1 \%)$ & $11(4.1 \%)$ \\
\hline Gastrointestinal disease & $1(3.8 \%)$ & $1(1.8 \%)$ & $4(1.5 \%)$ \\
\hline Neuropsychiatric disease & $0(0 \%)$ & $1(1.8 \%)$ & $6(2.2 \%)$ \\
\hline Trauma & $1(3.8 \%)$ & $2(3.6 \%)$ & $5(1.9 \%)$ \\
\hline Renal disease & $0(0 \%)$ & $1(1.8 \%)$ & $3(1.1 \%)$ \\
\hline Diabetes mellitus & $0(0 \%)$ & $1(1.8 \%)$ & $5(1.9 \%)$ \\
\hline Other cause & $2(7.7 \%)$ & $1(1.8 \%)$ & $5(1.9 \%)$ \\
\hline Unknown cause & $2(7.7 \%)$ & $3(5.4 \%)$ & $13(4.8 \%)$ \\
\hline Stage II ( $N=801$ deaths) & $(N=70)$ & $(N=127)$ & $(N=604)$ \\
\hline Colon cancer & $32(45.7 \%)$ & $50(39.4 \%)$ & $222(36.7 \%)$ \\
\hline Cardiovascular disease & $6(8.6 \%)$ & $28(22.0 \%)$ & $204(33.8 \%)$ \\
\hline Respiratory disease & $4(5.7 \%)$ & $6(4.7 \%)$ & $50(8.3 \%)$ \\
\hline Other primary cancer & $10(14.3 \%)$ & $15(11.8 \%)$ & $39(6.5 \%)$ \\
\hline Infection & $2(2.9 \%)$ & $4(3.1 \%)$ & 25 (4.1\%) \\
\hline Gastrointestinal disease & $4(5.7 \%)$ & $8(6.3 \%)$ & $10(1.7 \%)$ \\
\hline Neuropsychiatric disease & $1(1.4 \%)$ & $4(3.1 \%)$ & $5(0.8 \%)$ \\
\hline Trauma & $1(1.4 \%)$ & $2(1.6 \%)$ & $8(1.3 \%)$ \\
\hline Renal disease & $2(2.9 \%)$ & $1(0.8 \%)$ & $3(0.5 \%)$ \\
\hline Diabetes mellitus & $3(4.3 \%)$ & $3(2.4 \%)$ & $5(0.8 \%)$ \\
\hline Other cause & $2(2.9 \%)$ & $2(1.6 \%)$ & $6(1.0 \%)$ \\
\hline Unknown cause & $3(4.3 \%)$ & $4(3.1 \%)$ & $27(4.5 \%)$ \\
\hline Stage III ( $N=1020$ deaths) & $(N=130)$ & $(N=218)$ & $(N=672)$ \\
\hline Colon cancer & $90(69.2 \%)$ & $123(56.4 \%)$ & 395 (58.8\%) \\
\hline Cardiovascular disease & $10(7.7 \%)$ & 34 (15.6\%) & $117(17.4 \%)$ \\
\hline Respiratory disease & $4(3.1 \%)$ & $11(5.0 \%)$ & $30(4.5 \%)$ \\
\hline Other primary cancer & $9(6.9 \%)$ & $15(6.9 \%)$ & $40(5.9 \%)$ \\
\hline Infection & $3(2.3 \%)$ & $12(5.5 \%)$ & $14(2.1 \%)$ \\
\hline Gastrointestinal disease & $3(2.3 \%)$ & $4(1.8 \%)$ & $13(1.9 \%)$ \\
\hline Neuropsychiatric disease & $0(0 \%)$ & $0(0 \%)$ & $12(1.9 \%)$ \\
\hline Trauma & $3(2.3 \%)$ & $1(0.5 \%)$ & $5(0.7 \%)$ \\
\hline Renal disease & $0(0 \%)$ & $0(0 \%)$ & $7(1.0 \%)$ \\
\hline Diabetes mellitus & $2(1.5 \%)$ & $4(1.8 \%)$ & $6(0.9 \%)$ \\
\hline Other cause & $1(0.8 \%)$ & $4(1.8 \%)$ & $28(0.7 \%)$ \\
\hline Unknown cause & $5(3.8 \%)$ & $10(4.6 \%)$ & $28(4.2 \%)$ \\
\hline
\end{tabular}

recovered to or above baseline exercise capacity at 8 weeks compared with those who underwent rehabilitation after surgery (84\% vs 62\%, $P=0.049$; Gillis et al, 2014). As aforementioned, CGA and involvement of geriatricians in postoperative care for selected patients may help lower postoperative complication rates and length of stay (Huddleston et al, 2004; Partridge et al, 2014). Furthermore, there is evidence from the United Kingdom that CGA is associated with higher rates of chemotherapy completion and fewer treatment modifications in patients $\geqslant 70$ years old (Kalsi et al, 2015). This is particularly important as the present study observed that only $33 \%$ of patients $\geqslant 75$ year old, which comprised $44 \%$ of the study cohort, received adjuvant chemotherapy for stage III disease, and receipt of adjuvant chemotherapy significantly reduced the risk of 1-year overall and cancer-specific mortality. Due to a lack of compliance to evidence-based recommendations, an aging population, and a growing demand for cancer care, the Institute of Medicine recently declared that U.S. cancer care is in a state of crisis (Levit et al, 2013). Auditing and feedback regarding quality indicators, such as adjuvant chemotherapy administration for stage III disease, may help improve healthcare delivery and performance (Cirocco et al, 2014).

Although older patients undergoing elective colon cancer resection may benefit from CGA and prehabilitation, another important finding in this study was that older patients were more likely to undergo colon cancer resection during an unscheduled admission. Previous studies have indicated that non-elective colon 
Table 4. Multivariable analysis of factors independently associated with 1-year cause-specific mortality

\begin{tabular}{|c|c|c|}
\hline & $\begin{array}{c}\text { Death from } \\
\text { colon cancer } \\
\text { (hazard ratio } \\
(95 \% \mathrm{Cl}))\end{array}$ & $\begin{array}{c}\text { Death from } \\
\text { cardiovascular } \\
\text { disease (hazard } \\
\text { ratio }(95 \% \mathrm{CI}) \text { ) }\end{array}$ \\
\hline \multicolumn{3}{|l|}{ Age } \\
\hline$<65$ & Reference & Reference \\
\hline $65-74$ & $1.59(1.26-2.00)$ & $3.72(2.29-6.05)$ \\
\hline$\geqslant 75$ & $2.57(2.09-3.16)$ & $7.02(4.44-11.10)$ \\
\hline \multicolumn{3}{|l|}{ Postoperative complication } \\
\hline Sepsis & $2.58(2.13-3.11)$ & $2.33(1.81-2.99)$ \\
\hline Pneumonia & $2.15(1.39-3.34)$ & $2.37(1.44-3.89)$ \\
\hline Abdominal abscess & $1.57(1.18-2.08)$ & $1.19(0.77-1.84)$ \\
\hline Myocardial infarction & $1.49(1.10-2.03)$ & $1.59(1.12-2.25)$ \\
\hline Gastrointestinal bleeding & $1.08(0.85-1.37)$ & $1.42(1.08-1.86)$ \\
\hline \multicolumn{3}{|l|}{ Other patient factors } \\
\hline \multicolumn{3}{|l|}{ Comorbidities } \\
\hline Congestive heart failure & $1.20(1.01-1.43)$ & $2.38(1.95-2.91)$ \\
\hline Peripheral vascular disease & $0.96(0.74-1.24)$ & $1.86(1.44-2.41)$ \\
\hline Renal failure & $1.11(0.88-1.39)$ & $1.73(1.35-2.21)$ \\
\hline Anaemia & $1.53(1.27-1.84)$ & $1.03(0.79-1.34)$ \\
\hline Unscheduled admission & $1.85(1.59-2.14)$ & $1.51(1.23-1.84)$ \\
\hline Blood transfusion & $1.16(1.01-1.34)$ & $1.19(0.98-1.44)$ \\
\hline Discharge to healthcare facility & $1.50(1.29-1.75)$ & $2.68(2.19-3.27)$ \\
\hline \multicolumn{3}{|l|}{ Oncologic factors } \\
\hline \multicolumn{3}{|l|}{ AJCC stage } \\
\hline 1 & Reference & Reference \\
\hline$\|$ & $2.14(1.66-2.77)$ & $1.10(0.89-1.37)$ \\
\hline III & $5.40(4.20-6.94)$ & $0.97(0.77-1.23)$ \\
\hline \multicolumn{3}{|l|}{ Tumour grade } \\
\hline 1 & Reference & - \\
\hline 2 & $1.06(0.78-1.42)$ & - \\
\hline $3 / 4$ & $2.24(1.65-3.04)$ & - \\
\hline Unknown & $2.01(1.32-3.07)$ & - \\
\hline Receipt of adjuvant chemotherapy & $0.66(0.55-0.78)$ & - \\
\hline \multicolumn{3}{|l|}{ Operative factors } \\
\hline \multicolumn{3}{|l|}{ Type of colectomy } \\
\hline Right & Reference & Reference \\
\hline Left & $1.15(1.00-1.33)$ & $1.04(0.86-1.27)$ \\
\hline Partial & $1.30(0.94-1.79)$ & $1.13(0.74-1.73)$ \\
\hline Total & $1.15(0.64-2.06)$ & $1.10(0.51-2.37)$ \\
\hline \multicolumn{3}{|l|}{ Operative approach } \\
\hline Open & Reference & Reference \\
\hline Minimally invasive & $0.77(0.63-0.94)$ & $0.89(0.68-1.16)$ \\
\hline \multicolumn{3}{|l|}{ Year of surgery } \\
\hline 2004-2005 & Reference & Reference \\
\hline $2006-2007$ & $0.86(0.72-1.01)$ & $0.92(0.74-1.15)$ \\
\hline 2008-2009 & $0.92(0.78-1.10)$ & $0.85(0.67,1.09)$ \\
\hline $2010-2011$ & $0.61(0.50-0.76)$ & $0.51(0.38-0.68)$ \\
\hline \multicolumn{3}{|l|}{ Surgeon factors } \\
\hline \multicolumn{3}{|l|}{ Board-certification } \\
\hline Surgery & Reference & Reference \\
\hline Colorectal surgery & $0.77(0.62-0.94)$ & $0.82(0.62-1.07)$ \\
\hline \multicolumn{3}{|l|}{ Annual colon cancer resection volume } \\
\hline Low $(1-5)$ & Reference & Reference \\
\hline Medium (5-10) & $0.86(0.74-1.01)$ & $1.11(0.89-1.38)$ \\
\hline High $(>10)$ & $0.83(0.71-0.98)$ & $1.09(0.87-1.37)$ \\
\hline
\end{tabular}

cancer surgery is associated with worse survival, and non-elective presentation would preclude the use of preoperative CGA and prehabilitation (Gooiker et al, 2012; Dekker et al, 2014). This finding highlights the importance of adherence to colon cancer screening guidelines. In addition, older patients were more likely to undergo open colectomy and have surgery at rural or nonacademic institutions. An open approach has been shown to have higher morbidity compared with a minimally invasive approach, and rural and non-academic institutions may not have the resource availability for CGA, prehabilitation, and multidisciplinary care
(Bilimoria et al, 2008). Identifying strategies to improve adherence to colon cancer screening guidelines to limit the number of nonelective colon cancer resections, increase the rate of a minimally invasive approach, and either increase resource availability or develop a standardised algorithm to select patients for CGA and prehabilitation may further improve outcomes for older patients.

Given that cardiovascular disease was the second-leading cause of 1-year mortality following colon cancer surgery, CGA, multidisciplinary care, and management of patient comorbidities among surgeons, primary care physicians, and medical oncologists may further help improve patient survival (Kim et al, 2010; Brar et al, 2014). Because $66 \%$ of the study cohort had stage I or II colon cancer, it is plausible that the majority of patients never saw a medical oncologist following surgery. If these patients are elderly, have medical comorbidities, or are current smokers and do not have regular follow-up with their primary care physicians, they may be at higher risk for cardiovascular events in the postoperative period as their medical conditions are not being optimally managed. A recent study found that hypertension, diabetes mellitus, and smoking history were the strongest predictors of cardiovascular disease in breast cancer survivors $\geqslant 65$ years old (Haque et al, 2014). Not surprisingly, several studies have observed that cancer patients with a comorbidity had worse 5-year survival compared with those without comorbidity, with hazard ratios ranging from 1.1 to 5.8 (Finlayson et al, 2007; Sogaard et al, 2013). Furthermore, older age was associated with septic complications in the present study, and there is increasing evidence that sepsis is not only associated with an increased risk of cancer-related mortality but also cardiovascular events (Yende et al, 2014; Ou et al, 2016; Park et al, 2016). The underlying mechanism for this cardiovascular risk is thought to be due to sepsis-mediated systemic inflammation. There has been some evidence that the use of statins may suppress the inflammatory response to sepsis, thus reducing the risk of cardiovascular events (Steiner et al, 2005). However, further studies investigating the use of statins in sepsis survivorship are needed.

Study weaknesses and strengths. Although this exploratory study identified several potential targets to improve survival following colon cancer surgery, it has several limitations. First, SPARCS relies on administrative coding and does not include a comprehensive list of comorbidities, physician and patient decision-making, or information regarding patient functional dependence, ADLs, IADLs, and frailty. In addition, the timing of postoperative complications with respect to the date of surgery is not captured in SPARCS. Furthermore, although information regarding receipt of adjuvant chemotherapy is available, there is no data regarding the number of cycles or which chemotherapy agents were administered. Notwithstanding these limitations, this is the largest study in the United States to investigate the relationship among age, postoperative complications, 1-year survival, and cause of death following colon cancer surgery. In addition, SPARCS is an all-payer database including patients of all ages, and the data are linked to the state cancer registry to obtain information regarding oncologic staging and adjuvant therapy. It is also linked to the National Death Index, which enables capturing of the date and cause of death for patients as long as they died within the United States, which is an advantage over single-institution studies which may have limited follow-up.

\section{CONCLUSIONS}

This study demonstrated that older age is independently associated with higher odds of postoperative complications, and older age and complications, in particular sepsis, are associated with higher rates of 1-year overall, cancer-specific, and cardiovascular disease- 
specific mortality following potentially curative colon cancer surgery. These findings highlight the importance of CGA and multidisciplinary care among surgeons, primary care physicians, and oncologists for older patients. The study also demonstrates the need for future work identifying methods of cardiovascular optimisation in elderly patients and sepsis survivors following surgery given their increased risk of 1-year mortality from cardiovascular disease.

\section{CONFLICT OF INTEREST}

FJF received personal fees from UpToDate unrelated to the current work. The other authors have no conflicts of interest to report.

Oral presentation at 2016 American Society of Clinical Oncology Annual Meeting, Chicago, IL, 6 June 2016.

\section{REFERENCES}

Aquina CT, Blumberg N, Becerra AZ, Boscoe FP, Schymura MJ, Noyes K, Monson JR, Fleming FJ (2016a) Association among blood transfusion, sepsis, and decreased long-term survival after colon cancer resection. Ann Surg; e-pub ahead of print 14 September 2016; doi:10.1097/ SLA.0000000000001990.

Aquina CT, Blumberg N, Probst CP, Becerra AZ, Hensley BJ, Iannuzzi JC, Gonzalez MG, Deeb AP, Noyes K, Monson JR, Fleming FJ (2015a) Significant variation in blood transfusion practice persists following upper GI cancer resection. J Gastrointest Surg 19(11): 1927-1937.

Aquina CT, Blumberg N, Probst CP, Becerra AZ, Hensley BJ, Noyes K, Monson JR, Fleming FJ (2016b) Large variation in blood transfusion use after colorectal resection: a call to action. Dis Colon Rectum 59(5): 411-418.

Aquina CT, Kelly KN, Probst CP, Iannuzzi JC, Noyes K, Langstein HN, Monson JR, Fleming FJ (2015b) Surgeon volume plays a significant role in outcomes and cost following open incisional hernia repair. J Gastrointest Surg 19(1): 100-110.

Aquina CT, Probst CP, Becerra AZ, Hensley BJ, Iannuzzi JC, Noyes K, Monson JR, Fleming FJ (2016c) High variability in nosocomial clostridium difficile infection rates across hospitals after colorectal resection. Dis Colon Rectum 59(4): 323-331.

Aquina CT, Probst CP, Becerra AZ, Iannuzzi JC, Hensley BJ, Noyes K, Monson JR, Fleming FJ (2015c) Missed opportunity: laparoscopic colorectal resection is associated with lower incidence of small bowel obstruction compared to an open approach. Ann Surg 264(1): 127-134.

Aquina CT, Probst CP, Becerra AZ, Iannuzzi JC, Kelly KN, Hensley BJ, Rickles AS, Noyes K, Fleming FJ, Monson JR (2016d) High volume improves outcomes: the argument for centralization of rectal cancer surgery. Surgery 159(3): 736-748.

Aquina CT, Probst CP, Kelly KN, Iannuzzi JC, Noyes K, Fleming FJ, Monson JR (2015d) The pitfalls of inguinal herniorrhaphy: surgeon volume matters. Surgery 158(3): 736-746.

Bilimoria KY, Bentrem DJ, Merkow RP, Nelson H, Wang E, Ko CY, Soper NJ (2008) Laparoscopic-assisted vs. open colectomy for cancer: comparison of short-term outcomes from 121 hospitals. J Gastrointest Surg 12(11): 2001-2009.

Boscoe FP, Schrag D, Chen K, Roohan PJ, Schymura MJ (2011) Building capacity to assess cancer care in the Medicaid population in New York State. Health Serv Res 46(3): 805-820.

Brar SS, Hong NL, Wright FC (2014) Multidisciplinary cancer care: does it improve outcomes? J Surg Oncol 110(5): 494-499.

Byrne BE, Mamidanna R, Vincent CA, Faiz O (2013) Population-based cohort study comparing 30- and 90-day institutional mortality rates after colorectal surgery. Br J Surg 100(13): 1810-1817.

Cirocco WC, Steele SR, Buie WD (2014) Advancing standards of rectal cancer care: lessons from Europe adapted to the vast expanse of North America. Dis Colon Rectum 57(2): 260-266.

Dekker JW, Gooiker GA, Bastiaannet E, van den Broek CB, van der Geest LG, van de Velde CJ, Tollenaar RA, Liefers GJ, Steering Committee of the 'Quality Information System Colorectal Cancer P (2014) Cause of death the first year after curative colorectal cancer surgery; a prolonged impact of the surgery in elderly colorectal cancer patients. Eur J Surg Oncol 40(11): 1481-1487.

Dekker JW, van den Broek CB, Bastiaannet E, van de Geest LG, Tollenaar RA, Liefers GJ (2011) Importance of the first postoperative year in the prognosis of elderly colorectal cancer patients. Ann Surg Oncol 18(6): 1533-1539.

Ellis G, Whitehead MA, O’Neill D, Langhorne P, Robinson D (2011) Comprehensive geriatric assessment for older adults admitted to hospital. Cochrane Database Syst Rev (7): CD006211.

Extermann M (2010) Geriatric oncology: an overview of progresses and challenges. Cancer Res Treat 42(2): 61-68.

Finlayson E, Fan Z, Birkmeyer JD (2007) Outcomes in octogenarians undergoing high-risk cancer operation: a national study. J Am Coll Surg 205(6): 729-734.

Gillis C, Li C, Lee L, Awasthi R, Augustin B, Gamsa A, Liberman AS, Stein B, Charlebois P, Feldman LS, Carli F (2014) Prehabilitation versus rehabilitation: a randomized control trial in patients undergoing colorectal resection for cancer. Anesthesiology 121(5): 937-947.

Gooiker GA, Dekker JW, Bastiaannet E, van der Geest LG, Merkus JW, van de Velde CJ, Tollenaar RA, Liefers GJ (2012) Risk factors for excess mortality in the first year after curative surgery for colorectal cancer. Ann Surg Oncol 19(8): 2428-2434.

Haque R, Prout M, Geiger AM, Kamineni A, Thwin SS, Avila C, Silliman RA, Quinn V, Yood MU (2014) Comorbidities and cardiovascular disease risk in older breast cancer survivors. Am J Manag Care 20(1): $86-92$.

Huddleston JM, Long KH, Naessens JM, Vanness D, Larson D, Trousdale R, Plevak M, Cabanela M, Ilstrup D, Wachter RM, Hospitalist-Orthopedic Team Trial I (2004) Medical and surgical comanagement after elective hip and knee arthroplasty: a randomized, controlled trial. Ann Intern Med 141(1): 28-38.

Iannuzzi JC, Aquina CT, Rickles AS, Hensley BJ, Probst CP, Noyes K, Monson JR, Fleming FJ (2016) Risk factors for postdischarge venothromboembolism after colorectal resection. Dis Colon Rectum 59(3): 224-229.

Kalsi T, Babic-Illman G, Ross PJ, Maisey NR, Hughes S, Fields P, Martin FC, Wang Y, Harari D (2015) The impact of comprehensive geriatric assessment interventions on tolerance to chemotherapy in older people. Br J Cancer 112(9): 1435-1444.

Katsahian S, Resche-Rigon M, Chevret S, Porcher R (2006) Analysing multicentre competing risks data with a mixed proportional hazards model for the subdistribution. Stat Med 25(24): 4267-4278.

Kim MM, Barnato AE, Angus DC, Fleisher LA, Kahn JM (2010) The effect of multidisciplinary care teams on intensive care unit mortality. Arch Intern Med 170(4): 369-376.

Levit LA, Balogh E, Nass SJ, Ganz P, Institute of Medicine (US), Committee on Improving the Quality of Cancer Care: Addressing the Challenges of an Aging Population. (2013) Delivering High-Quality Cancer Care Charting a New Course for a System in Crisis, p 384. National Academies Press: Washington, D.C.

Makary MA, Segev DL, Pronovost PJ, Syin D, Bandeen-Roche K, Patel P, Takenaga R, Devgan L, Holzmueller CG, Tian J, Fried LP (2010) Frailty as a predictor of surgical outcomes in older patients. J Am Coll Surg 210(6): 901-908.

Mamidanna R, Almoudaris AM, Faiz O (2012a) Is 30-day mortality an appropriate measure of risk in elderly patients undergoing elective colorectal resection? Colorectal Dis 14(10): 1175-1182.

Mamidanna R, Burns EM, Bottle A, Aylin P, Stonell C, Hanna GB, Faiz O (2012b) Reduced risk of medical morbidity and mortality in patients selected for laparoscopic colorectal resection in England: a populationbased study. Arch Surg 147(3): 219-227.

Mohile SG, Hurria A, Cohen HJ, Rowland JH, Leach CR, Arora NK, Canin B, Muss HB, Magnuson A, Flannery M, Lowenstein L, Allore HG, Mustian KM, Demark-Wahnefried W, Extermann M, Ferrell B, Inouye SK, Studenski SA, Dale W (2016) Improving the quality of survivorship for older adults with cancer. Cancer 122(16): 2459-2568.

Oresanya LB, Lyons WL, Finlayson E (2014) Preoperative assessment of the older patient: a narrative review. JAMA 311(20): 2110-2120.

Ou SM, Chu H, Chao PW, Lee YJ, Kuo SC, Chen TJ, Tseng CM, Shih CJ, Chen YT (2016) Long-term mortality and major adverse cardiovascular events in sepsis survivors: a nationwide population-based study. Am J Respir Crit Care Med 194(2): 209-217. 
Park JH, Watt DG, Roxburgh CS, Horgan PG, McMillan DC (2016) Colorectal cancer, systemic inflammation, and outcome: staging the tumour and staging the host. Ann Surg 263(2): 326-336.

Partridge JS, Harari D, Martin FC, Dhesi JK (2014) The impact of preoperative comprehensive geriatric assessment on postoperative outcomes in older patients undergoing scheduled surgery: a systematic review. Anaesthesia 69(Suppl 1): 8-16.

Quan H, Sundararajan V, Halfon P, Fong A, Burnand B, Luthi JC, Saunders LD, Beck CA, Feasby TE, Ghali WA (2005) Coding algorithms for defining comorbidities in ICD-9-CM and ICD-10 administrative data. Med Care 43(11): 1130-1139.

Robinson TN, Eiseman B, Wallace JI, Church SD, McFann KK, Pfister SM, Sharp TJ, Moss M (2009) Redefining geriatric preoperative assessment using frailty, disability and co-morbidity. Ann Surg 250(3): 449-455.

Siegel R, Ma J, Zou Z, Jemal A (2014) Cancer statistics, 2014. CA Cancer J Clin 64(1): 9-29.
Sogaard M, Thomsen RW, Bossen KS, Sorensen HT, Norgaard M (2013) The impact of comorbidity on cancer survival: a review. Clin Epidemiol 5(Suppl 1): 3-29.

Steiner S, Speidl WS, Pleiner J, Seidinger D, Zorn G, Kaun C, Wojta J, Huber K, Minar E, Wolzt M, Kopp CW (2005) Simvastatin blunts endotoxin-induced tissue factor in vivo. Circulation 111(14): 1841-1846.

United States Department of Agriculture Economic Research Service (2013) Rural classifications: United States Department of Agriculture Economic Research Service.

Yende S, Linde-Zwirble W, Mayr F, Weissfeld LA, Reis S, Angus DC (2014) Risk of cardiovascular events in survivors of severe sepsis. Am J Respir Crit Care Med 189(9): 1065-1074.

This work is published under the standard license to publish agreement. After 12 months the work will become freely available and the license terms will switch to a Creative Commons AttributionNonCommercial-Share Alike 4.0 Unported License.

Supplementary Information accompanies this paper on British Journal of Cancer website (http://www.nature.com/bjc) 